\title{
Effects of various starch feeding regimens on responses of dairy cows to intramammary lipopolysaccharide infusion
}

\author{
P. N. Gott, J. S. Hogan, and W. P. Weiss ${ }^{1}$ \\ Department of Animal Sciences, Ohio Agricultural Research and Development Center, The Ohio State University, Wooster 44691
}

\begin{abstract}
Endotoxin tolerance (ET) can develop in mammals that have been challenged repeatedly with sublethal amounts of lipopolysaccharide (LPS). Previous research has shown that subclinical ruminal acidosis can increase circulating concentrations of LPS. We investigated whether ET would develop in Holstein cows that were subjected to chronic subacute ruminal acidosis (SARA) or acute SARA followed by intramammary infusion of LPS. Twenty-four cows, both primiparous and multiparous, were assigned to 8 blocks of 3 cows. Cows within blocks were randomly assigned to 1 of 3 treatments: (1) control (diet DM was $24 \%$ starch and $35 \%$ NDF), (2) high starch (formulated to induce chronic milk fat depression with 29\% starch and $32 \% \mathrm{NDF}$ ), and (3) acidosis (designed to cause acute bouts of milk fat depression by short-term feeding of a diet with $32 \%$ starch, some of which came from wheat grain, and $30 \%$ NDF). Cows on the control and high-starch treatments were fed their respective diets throughout the $24-d$ trial. The acidosis cows were fed the control diet during most of the experiment, except during two 2-d bouts (d 10 and 11 and 17 and 18 of the experiment) in which a high-starch diet was fed. Cows on the highstarch and acidosis treatments produced milk fat with an altered fatty acid profile indicative of SARA (e.g., increased concentrations of specific trans, and odd-, and branched-chain fatty acids), but only cows on the high-starch treatment had milk fat depression. Concentrations of serum amyloid A were elevated in cows on the acidosis treatment, but did not differ between control and high-starch cows. On d 20 of the experiment, all cows were given an intramammary infusion of 10 $\mu \mathrm{g}$ of LPS into 1 mammary quarter $3 \mathrm{~h}$ after morning milking. Milk yield and DMI decreased the day of the infusion, but the response was not affected by dietary treatment. No systemic indicators of ET were observed among treatments, but evidence of an ET response at the local level of the mammary gland was observed.
\end{abstract}

Received July 18, 2014.

Accepted November 22, 2014.

${ }^{1}$ Corresponding author: weiss.6@osu.edu
Cows fed the control diet had higher concentrations of serum amyloid A in milk 12 and $24 \mathrm{~h}$ postinfusion than did cows fed the high-starch diet and higher concentrations than cows on the acidosis treatment at 12 $\mathrm{h}$ postinfusion. Our data suggest cows that experienced varying degrees of SARA (based on altered milk fatty acid profile) and subsequent experimental endotoxin mastitis experienced a blunted inflammatory response at the level of the mammary gland, but not a systemic reduction in some inflammatory mediators.

Key words: ruminal acidosis, endotoxin, acute phase response

\section{INTRODUCTION}

Subclinical ruminal acidosis in cattle is associated with feeding diets with excess starch. Common signs of SARA include low rumen $\mathrm{pH}$, decreased DMI, diarrhea, deceased milk yield, milk fat depression, and altered milk FA profile (Garrett et al., 1999; Kleen et al., 2003; Colman et al., 2010). Increasing the starch concentration of diets can alter the rumen bacterial population by promoting growth of some gram-positive bacteria at the expense of gram-negative bacteria (Nagaraja et al., 1978). When gram-negative bacteria die they shed LPS from their cell wall (Beutler and Rietschel, 2003), and starch-induced SARA increases concentrations of LPS in rumen fluid and blood (Gozho et al., 2005; Gozho et al., 2006; Emmanuel et al., 2008; Khafipour et al., 2009). Concentrations of circulating acute phase proteins, such as serum amyloid A and haptogloblin (although not all studies were consistent for the different acute phase proteins), also increase with SARA (Gozho et al., 2005; Gozho et al., 2006; Emmanuel et al., 2008; Khafipour et al., 2009), perhaps as part of an inflammatory response to LPS. Mastitis caused by gram-negative bacteria also increase circulating concentrations of LPS (Hogan and Smith, 2003)

Endotoxin tolerance (ET) can develop in mammals that have been challenged repeatedly with sublethal amounts of LPS (Beeson, 1947). Tolerant animals experience a blunted inflammatory response to subsequent exposure to LPS (Beeson, 1947; Beutler and Rietschel, 2003), often quantified as decreased produc- 
tion of proinflammatory mediators (Sanchez-Cantu et al., 1989). Endotoxin tolerance is not fully understood, but is thought to be a host defense mechanism to prevent damage from excessive inflammation. However, the attenuated inflammatory response resulting from ET may increase the risk of infections becoming established. Some data suggest that ET can develop in calves, but the response has not been universal to all measurements of inflammation (Elsasser et al., 1996; Bieniek et al., 1998).

We hypothesized that cows experiencing chronic or sporadic bouts of SARA would exhibit ET when subsequently challenged with experimental LPS mastitis. If this occurs, cows with SARA may be more susceptible to subsequent problems with mastitis or other infections because of the potential immunosuppressive effects of ET. The aims of our experiment were to induce chronic SARA and sporadic bouts of SARA in dairy cows by feeding excess starch and then administer LPS into the mammary gland and evaluate local and systemic signs of inflammation.

\section{MATERIALS AND METHODS}

\section{Cows and Treatments}

All procedures involving animals were approved by The Ohio State University Institutional Animal Care and Use Committee. Twenty-four midlactation Holstein cows averaging $140(\mathrm{SD}=16)$ DIM were assigned to 8 blocks (3 cows per block) based on parity (4 blocks of primiparous and 4 blocks of multiparous) and DIM within parity. Cows were moved into the tiestall barn in 4 groups ( 2 blocks per group) every 2 wk. Cows had free access to water, were fed a TMR once daily (approximately $0330 \mathrm{~h}$ ) for ad libitum consumption (feed refusal averaged $5.8 \%$ of amount fed), and were milked twice daily (0300 and 1500 h). Feed offered and orts were measured daily and milk weights were recorded electronically at each milking. Cows selected for the trial did not have a diagnosed gram-negative bacterial IMI or clinical mastitis during the lactation before LPS challenge, as recorded on barn health sheets.

Cows within each block were randomly assigned to 1 of 3 dietary treatments: (1) control, (2) high starch, and (3) acidosis bouts. The control and high-starch diets differed in starch (essentially all the starch was from corn products), NDF, and forage NDF concentrations (Tables 1 and 2). In a previous experiment (Weiss, 2012), cows fed a diet similar to the high-starch diet had reduced milk fat percentage compared with cows fed a diet similar to the control diet. Cows on those 2 treatments were fed the same diet each day during the 24-d experiment. The high-starch diet was used to elicit longer term effects (i.e., chronic) on rumen fermentation. Cows on the acidosis bout treatment were fed the control diet during most of the experiment, except during two 2-d bouts (d 10-11 and 17-18) when they were fed a diet where $9.7 \%$ ground wheat replaced a portion of a wet corn gluten feed product (Tables 1 and 2). The diet fed during the bouts was higher in starch and lower in NDF concentrations than the other diets, and approximately $20 \%$ of the starch came from wheat. The acidosis challenge was less severe than other models (e.g., Keunen et al., 2002), but was similar to diets that have induced some short-term changes in rumen fermentation patterns (Colman et al., 2010). This treatment was designed to elicit short-term, abrupt, and repeated changes in rumen fermentation patterns. All diets were formulated to be equal in metabolizable protein (assuming no treatment effects on DMI), vitamins, and minerals and met or exceeded NRC (2001) recommendations.

On d 20 of the experimental period, all cows were given an intramammary infusion of LPS via teat canal into either front mammary quarter using a $34-\mathrm{mm}$ sterile teat infusion cannula (Jorgensen Laboratories Inc., Loveland, CO). The challenge inoculum was $10 \mu \mathrm{g}$ of LPS diluted in $10 \mathrm{~mL}$ of sterile PBS. The LPS was from Escherichia coli serotype O111:B4 (Sigma-Aldrich Company, St. Louis, MO). Challenge quarters were determined based on bacteriological and cytological results of quarter foremilk samples taken at $\mathrm{d} 7,5$, and 3 before challenge. Quarters selected were bacteriologi-

Table 1. Ingredient composition of treatment diets (\% of DM)

\begin{tabular}{lccc}
\hline & \multicolumn{3}{c}{ Treatment diet $^{1}$} \\
\cline { 2 - 4 } Item & Control & $\begin{array}{c}\text { High } \\
\text { starch }\end{array}$ & Acidosis \\
\hline Corn silage & 44.0 & 36.0 & 36.0 \\
Alfalfa silage & 11.0 & 9.0 & 9.0 \\
Wet corn milling product ${ }^{2}$ & 25.0 & 25.0 & 10.0 \\
Corn grain, ground & 9.9 & 19.9 & 19.9 \\
Wheat grain, ground & 0 & 0 & 9.7 \\
Soybean meal, 48\% CP & 3.90 & 6.3 & 8.4 \\
Aminoplus & 3.50 & 1.0 & 4.2 \\
Animal-vegetable fat & 0.62 & 0.62 & 0.62 \\
Trace mineralized salt & 0.50 & 0.50 & 0.50 \\
Limestone $_{\text {Vitamin-mineral premix }}{ }^{3}$ & 1.10 & 1.20 & 1.20 \\
l. & 0.48 & 0.48 & 0.48 \\
\hline
\end{tabular}

${ }^{1}$ Cows on the control and high-starch treatments were fed their respective diets continuously during the experiment. The acidosis diet was fed to cows on the acidosis treatment for only two 2-d feeding bouts during the experiment.

${ }^{2}$ Cargill Corn Milling, NA, Blair, NE.

${ }^{3} \mathrm{Ag}$ Processing Inc., Omaha, NE.

${ }^{4}$ Premix provided $0.2 \mathrm{mg}$ of Se (from sodium selenate), $12 \mathrm{mg}$ of $\mathrm{Cu}$ (from copper sulfate), $22 \mathrm{mg}$ of $\mathrm{Zn}$ (from zinc sulfate), 3,600 IU of vitamin A, $990 \mathrm{IU}$ of vitamin D, $20 \mathrm{IU}$ of vitamin E, and $0.67 \mathrm{mg}$ of biotin (Rovimix-Biotin, DSM Nutritional Products Inc., Parsippany, $\mathrm{NJ})$ per kilogram of diet DM. 
Table 2. Nutrient composition of treatment diets

\begin{tabular}{lccc}
\hline & \multicolumn{3}{c}{ Treatment diet $^{1}$} \\
\cline { 2 - 4 } $\begin{array}{l}\text { Item, \% of DM } \\
\text { (unless otherwise noted) }\end{array}$ & Control & $\begin{array}{c}\text { High } \\
\text { starch }\end{array}$ & Acidosis \\
\hline $\mathrm{DM}$ & 51.0 & 54.9 & 56.1 \\
$\mathrm{CP}$ & 16.4 & 16.3 & 16.1 \\
$\mathrm{NDF}$ & 34.7 & 31.7 & 29.9 \\
Forage NDF & 23.6 & 19.3 & 19.3 \\
IVNDFD, ${ }^{2}$ \% of NDF & 53.5 & 55.8 & 55.2 \\
Starch & 24.1 & 28.5 & 32.0 \\
Long-chain FA & 3.3 & 3.4 & 2.7 \\
NE ${ }^{3}{ }^{2}$ Mcal/kg & 1.57 & 1.57 & 1.60 \\
Ca & 0.81 & 0.84 & 0.85 \\
$\mathrm{P}$ & 0.49 & 0.49 & 0.40 \\
$\mathrm{Mg}$ & 0.25 & 0.24 & 0.20 \\
$\mathrm{~K}$ & 1.43 & 1.31 & 1.17 \\
\hline
\end{tabular}

${ }^{1}$ Cows on the control and high-starch treatments were fed their respective diets continuously during the experiment. The acidosis diet was fed to cows on the acidosis treatment for only two 2-d feeding bouts during the experiment.

${ }^{2}$ In vitro NDF digestibility (30 h of incubation).

${ }^{3}$ Calculated (NRC, 2001).

cally negative and had an SCC $<250,000$ cells $/ \mathrm{mL}$ during the prechallenge sampling period. Quarters were infused $3 \mathrm{~h}$ after morning milking at $0600 \mathrm{~h}$ and were not fed until after their quarter was infused.

\section{Mammary Gland Challenge Measurements}

Quarter foremilk was sampled by aseptic techniques (NMC, 2004) immediately prior $(0 \mathrm{~h})$ to intramammary challenge and at $3,6,9,12,24,48,72$, and $168 \mathrm{~h}$ postchallenge for bacteriological and cytological examination (Hogan et al., 1992). Approximately $10 \mathrm{~mL}$ of quarter foremilk was collected into $15-\mathrm{mL}$ sterile tubes from each quarter that was sampled. Milk SCC were determined electronically using a Bentley Somacount 150 (Bentley Instruments Inc., Chaska, MN). Samples from mammary glands with clinical mastitis were diluted 1:50 in PBS before SCC were determined.

Clinical mastitis scores (Hogan et al., 1992) were assigned cow-side based on observation of foremilk, mammary quarter palpation, and general cow demeanor where $1=$ normal milk and normal quarter; $2=$ questionable milk and normal quarter; $3=$ abnormal milk, no detectable signs of swelling; $4=$ abnormal milk, detectable swelling; and $5=$ abnormal milk, detectable swelling, and systemic signs. Abnormalities found in milk that justified a score of 3 included flakes, clots, watery appearance, or serum-like appearance. Swelling or firmness, heat, and reddening of the udder skin were all indications of inflammation of the mammary quarters. Prior to the LPS challenge, rectal temperatures and rumen contractions were measured once daily for all cows on d 10, 11, 17, and 18 (days during acidosis bouts). Rectal temperatures were recorded with digital thermometers. Rumen contractions were quantified by auscultation (Perkins et al., 2002). Rectal temperatures and rumen contractions were also recorded at $0,3,6$, 9, 12, 24, 48, 72, and 168 (rectal temperature only) h post-LPS challenge.

\section{Feed Sampling and Analyses}

Feeds were sampled weekly and a subsample of each silage was assayed for $\mathrm{DM}\left(100^{\circ} \mathrm{C}\right.$ for $\left.48 \mathrm{~h}\right)$ to adjust asfed amounts. Remaining samples were frozen $\left(-20^{\circ} \mathrm{C}\right)$ and composited by month $(\mathrm{n}=3)$. During the two 2 -d bouts when the acidosis diet was fed, the acidosis challenge concentrate and the corn silage was sampled daily and assayed for DM, starch, and NDF. Feed refusals were sampled from every cow on d 7 and 14 and, because of the potential of sorting by cows when fed an acidosis challenge diet (Keunen et al., 2002), refusals were sampled from cows on the acidosis treatment each day during the two 2-d bouts and assayed for DM and starch (the starch concentrations shown in Table 2 reflect the actual average consumption of starch by acidosis bout cows). The DM values for $\mathrm{d} 7$ and 14 were averaged within a cow and used to calculate DMI for the entire experiment, except during the acidosis bouts when actual daily DM values of refusals were used.

Samples of the silages and the wet corn gluten feed product were dried $\left(55^{\circ} \mathrm{C}\right.$ for $\left.24 \mathrm{~h}\right)$ and ground through a 1-mm screen (Wiley Mill, Arthur A. Thomas, Philadelphia, PA). Dry concentrate mixes were not ground before analysis. Feed samples were analyzed for NDF $\left(\right.$ Ankom $^{200}$ Fiber Analyzer, Ankom Technology, Fairport, NY) with sodium sulfite and amylase (Sigma A3306, Sigma Diagnostics, St. Louis, MO), ash $\left(600^{\circ} \mathrm{C}\right.$ overnight), CP (Method 984.13.4.2.09; AOAC International, 2000), starch (Weiss and Wyatt, 2000), and long-chain FA (Weiss and Wyatt, 2003). Monthly forage composites were dry-ashed and monthly samples of concentrates and wet corn gluten feed product were digested with perchloric acid (AOAC International, 2000); mineral concentrations were determined using inductively coupled plasma emission spectroscopy. Monthly TMR samples for each diet were prepared from dry, ground monthly composite samples of ingredients and were assayed for $30-\mathrm{h}$ in vitro ruminal NDF digestibility by Cumberland Valley Analytical Services (Hagerstown, MD) following the procedure of Goering and Soest (1970), except for the NDF assay, which was as described by Van Soest et al. (1991).

\section{Blood and Milk Sampling and Analysis}

Milk samples (morning and evening) were taken during regular milking on $\mathrm{d} 7,11,14,18$, and 21 and 
assayed for fat, protein, and lactose using a B2000 Infrared Analyzer (Bentley Instruments Inc., Chaska, MN), and for MUN (Skalar SAN Plus segmented flow analyzer, Skalar Inc., Norcross, GA) by DHI Cooperative Inc. (Columbus, OH). Milk was also sampled from the morning milking on d 10,11, 13, 17, 18, 20, and 24 and assayed for milk FA using the 2-step methylation procedure (Kramer et al., 1997) and quantified using GLC. All FA were quantified using nonadecanoic acid (C19:0, Nuchek Prep Inc., Elysian, MN) as an internal standard. Fatty acid peaks were identified using various mixtures of purchased standards including: GLC68D and GLC60 (Nuchek Prep Inc.), Bacterial Acid Methyl Ester Mix, 47080-U and methyl 11-methyldodecanoate (Sigma-Aldrich), and GLC-110 (Matreya LLC, Pleasant Gap, PA). The d-10 and -17 samples were taken approximately $3 \mathrm{~h}$ before cows were fed the first SARA challenge of the first and second bout, respectively. The d-11 and -18 samples were taken approximately $20 \mathrm{~h}$ after the acidosis diet was first fed in the first and second bouts and the d-13 and - 20 samples were taken approximately $20 \mathrm{~h}$ after acidosis cows were changed back to the control diet following the first and second bouts. The d-20 sample was also approximately $4 \mathrm{~h}$ before the LPS challenge and the d-24 sample was approximately $4 \mathrm{~d}$ after the LPS challenge.

Blood samples were collected by coccygeal venipuncture from all cows at approximately $0700 \mathrm{~h}$ on $\mathrm{d} 11$ and 18 (approximately $24 \mathrm{~h}$ after the first feeding of the acidosis challenge diet for bouts 1 and 2, respectively). Blood was allowed to clot and serum was separated by centrifugation $\left(2,500 \times g\right.$ at $\left.10^{\circ} \mathrm{C}\right)$ and frozen $\left(-20^{\circ} \mathrm{C}\right)$ until assayed for serum amyloid A (SAA) using a commercial kit (Phase Range Multispecies SAA ELISA Kit, Tridelta Development Ltd., Maynooth, Ireland). The measuring range was 9.4 to $150 \mu \mathrm{g} / \mathrm{mL}$ with a sensitivity of $1.5 \mu \mathrm{g} / \mathrm{mL}$. Samples were diluted 1:500 per kit recommendations. Subsamples of quarter foremilk from the LPS-challenged quarters taken at 0,3 , $6,9,12$, and $24 \mathrm{~h}$ were frozen until assayed for milk amyloid A (MAA) using a commercial kit (Mast ID Range Milk Amyloid A Assay Kit, Tridelta Development Ltd.). The measuring range was 0.438 to $7.5 \mu \mathrm{g} /$ $\mathrm{mL}$ with a sensitivity of $0.10 \mu \mathrm{g} / \mathrm{mL}$. Samples were initially diluted 1:50 per kit directions. Samples with concentrations greater than the maximum reading were diluted up to 1:500 and retested. All samples were run in duplicate.

\section{Statistical Analysis}

This experiment was divided into 2 phases for statistical analysis, but the same basic statistical model was used for both phases. The first phase was from d 1 to 20 (i.e., before the intramammary LPS challenge). Data analyzed for this phase were production measures, milk FA, SAA, rectal temperatures, and rumen motility. Data were analyzed using Proc MIXED with the autoregressive covariance structure (SAS Institute, 2009). That covariance structure was chosen because it usually resulted in the lowest Bayesian information criterion. The model included the fixed effect of treatment ( $2 \mathrm{df})$, parity (1 df, primiparous vs. multiparous), block within parity (random, $6 \mathrm{df}$ ), time (fixed repeated measure with varying $d f$ depending on sampling schedule for the dependent variable), parity $\times$ treatment $(2 \mathrm{df})$, parity $\times$ time, treatment $\times$ time, and parity $\times$ treatment $\times$ time (df for time interactions varied depending on dependent variable), and error (df varied depending on number of time variables). The number of time points for various dependent variables were $19 \mathrm{~d}$ for DMI and milk yield, $4 \mathrm{~d}$ for milk composition, $6 \mathrm{~d}$ for milk FA, 2 $\mathrm{d}$ for SAA, and $8 \mathrm{~d}$ for rectal temperature and rumen motility. Treatment was partitioned into 2 single degree of freedom contrasts: control versus high-starch treatments and control versus acidosis bout treatment. For DMI and milk (variables with daily measurements), the day by treatment interaction was evaluated using the SLICE option when the interaction was significant $(P$ $>0.10)$. For other variables measured less frequently, the time by treatment interactions were evaluated using 4 orthogonal contrasts with time coded based on whether the day the sample was collected was during an acidosis bout. The first orthogonal contrast ( $2 \mathrm{df}$ ) was designed to determine whether the response to the 3 treatments differed on periods when the acidosis diet was fed compared with when the basal diet was fed (cows on control and high-starch diets were fed their respective diet on all days). The second contrast was designed to evaluate whether responses over time differed between the control and high-starch diets (i.e., treatments that were constant over time). The third and fourth contrasts, respectively, evaluated whether responses over time differed between cows on the acidosis treatment and control treatment or between cows on the acidosis treatment and high-starch diet.

The second phase (LPS challenge phase) started on d 20 and continued until d 23 (72 h post-LPS infusion). The model included treatment, time (repeated measure coded as day or hour post-LPS challenge), and time by treatment interaction. Data analyzed from this phase included DMI, milk yield, rectal temperatures, rumen motility, MAA, SCC, and mastitis score. Daily milk yields and DMI were measured for $3 \mathrm{~d}$, MAA, rumen motility, and rectal temperature were measured 6 times (immediately before challenge and 3, 6, 9, 12, and $24 \mathrm{~h}$ 
Table 3. Effect of treatment on production measures and milk composition

\begin{tabular}{|c|c|c|c|c|c|c|c|}
\hline \multirow[b]{2}{*}{ Item } & \multicolumn{3}{|c|}{ Treatment $^{1}$} & \multirow[b]{2}{*}{ SEM } & \multicolumn{3}{|c|}{ Contrast $^{2}$} \\
\hline & $\mathrm{C}$ & $\mathrm{H}$ & $\mathrm{A}$ & & $\mathrm{C}$ vs. $\mathrm{H}$ & C vs. A & Int \\
\hline $\mathrm{DMI},{ }^{3} \mathrm{~kg} / \mathrm{d}$ & 23.5 & 25.0 & 23.4 & 1.10 & $<0.02$ & $<0.9$ & - \\
\hline Milk yield ${ }^{3} \mathrm{~kg} / \mathrm{d}$ & 36.1 & 38.3 & 37.9 & 2.45 & $<0.30$ & $<0.40$ & - \\
\hline Milk protein, \% & 3.06 & 3.05 & 2.99 & 0.064 & $<0.8$ & $<0.19$ & NS \\
\hline MUN, mg/dL & 13.1 & 12.1 & 12.5 & 0.47 & $<0.04$ & $<0.18$ & $1,3,4$ \\
\hline Milk fat, $\%$ & 3.78 & 3.46 & 3.62 & 0.15 & $<0.01$ & $<0.16$ & NS \\
\hline \multicolumn{8}{|c|}{ Milk FA, ${ }^{4} \mathrm{~g} / \mathrm{kg}$ of total FA } \\
\hline SCFA & 323.7 & 322.3 & 305.9 & 5.4 & $<0.74$ & $<0.01$ & NS \\
\hline $\mathrm{C} 16: 0$ & 338.4 & 328.9 & 354.8 & 5.7 & $<0.02$ & $<0.01$ & NS \\
\hline LCFA & 345.4 & 357.0 & 345.0 & 10.2 & $<0.03$ & $<0.93$ & NS \\
\hline $\mathrm{C} 18: 1$ trans -10 & 5.8 & 9.1 & 7.6 & 1.8 & $<0.01$ & $<0.01$ & $1,3,4$ \\
\hline C-12 CLA trans-10 & 0.036 & 0.098 & 0.038 & 0.025 & $<0.01$ & $<0.92$ & NS \\
\hline iso-C13:0 & 0.33 & 0.30 & 0.30 & 0.013 & $<0.06$ & $<0.04$ & NS \\
\hline anteiso-C13:0 & 1.02 & 1.15 & 1.02 & 0.071 & $<0.01$ & $<0.9$ & 1,3 \\
\hline C13:0 & 2.56 & 3.14 & 2.89 & 0.21 & $<0.01$ & $<0.07$ & $1,3,4$ \\
\hline iso-C14:0 & 1.05 & 0.79 & 0.82 & 0.083 & $<0.01$ & $<0.02$ & $1,3,4$ \\
\hline iso-C15:0 & 2.08 & 1.93 & 1.98 & 0.062 & $<0.02$ & $<0.10$ & NS \\
\hline anteiso-C15:0 & 4.98 & 4.75 & 4.74 & 0.127 & $<0.06$ & $<0.06$ & $1,3,4$ \\
\hline C15:0 & 12.88 & 14.83 & 15.56 & 0.95 & $<0.06$ & $<0.01$ & $1,3,4$ \\
\hline iso-C16:0 & 2.62 & 2.22 & 2.26 & 0.148 & $<0.01$ & $<0.02$ & $1,3,4$ \\
\hline iso-C17:0 & 3.24 & 3.52 & 3.47 & 0.14 & $<0.01$ & $<0.03$ & NS \\
\hline Total odd-chain & 35.9 & 39.1 & 39.6 & 1.42 & $<0.03$ & $<0.01$ & $1,3,4$ \\
\hline Total branched-chain & 15.3 & 14.7 & 14.5 & 0.36 & $<0.05$ & $<0.02$ & $1,3,4$ \\
\hline
\end{tabular}

${ }^{1}$ Cows on the control $(\mathrm{C})$ and high-starch $(\mathrm{H})$ treatments were fed the diets continuously during the experiment. Cows on the acidosis (A) treatment were fed the control diet during most of the experiment but were fed an acidosis-inducing diet during two 2-d feeding bouts. These data are for the period before LPS infusion (d 1 through d 19).

${ }^{2}$ Main effect contrasts compared effects of longer term feeding of different starch concentrations (C vs. H) and effects of abrupt short-term feeding of higher starch (C vs. A). Interaction of treatment with time (Int) contrasts answered the following questions: $1=$ were effects of all treatments similar over sampling days? $2=$ were effects of $\mathrm{C}$ and $\mathrm{H}$ similar over sampling days? 3 = were effects of $\mathrm{C}$ and $\mathrm{A}$ similar over sampling days? 4 $=$ were effects of $\mathrm{H}$ and $\mathrm{A}$ similar over sampling days? $\mathrm{NS}=P>0.10$.

${ }^{3}$ For DMI and milk yield, all days (not only days in which milk was sampled) were included in the interaction term. The treatment by day interaction was significant for DMI $(P<0.01)$, but not for milk yield (interactions were not partitioned using contrasts).

${ }^{4} \mathrm{SCFA}=$ short-chain fatty acids $(<16 \mathrm{C}) ; \mathrm{LCFA}=$ long-chain fatty acids $(\mathrm{C}>16)$.

postchallenge). Milk SCC and clinical score were measured 8 times (immediately before challenge, and 3, 6, $9,12,24,48$, and $72 \mathrm{~h}$ postchallenge).

\section{RESULTS AND DISCUSSION}

Parity had expected effects on production measures (e.g., first lactation animals ate less and produced less milk than mature cows), but no interactions with time or treatment were observed for parity and will not be discussed. All results shown are averaged over parity.

\section{Pre-LPS Challenge Phase Production Measures}

Cows fed the high-starch diet had greater $(P<0.02)$ DMI than cows fed the control diet (Table 3). That difference was likely caused by the difference in forage NDF concentration. Cows on the acidosis regimen had similar DMI as cows fed the control diet, but day affected $(P<0.01)$ DMI for cows on the acidosis regimen whereas it did not $(P>0.15)$ for the other 2 diets (Figure 1). The first day of both acidosis bouts, cows fed the acidosis diet had greater DMI than previous days when they were fed the control diet, but then DMI decreased the next $2 \mathrm{~d}(1 \mathrm{~d}$ while fed the acidosis diet and the following day when switched back to the control diet). The higher DMI on the initial day of the bouts may have been caused by the difference in DM concentration of the diets (Table 2). McBeth et al. (2013) observed an increase in DMI for $1 \mathrm{~d}$ when cows were abruptly changed from a wetter diet to a drier diet. The acidosis diet was also lower in NDF than the control diet, but the lower NDF concentration was caused mostly by replacing a corn gluten product with wheat grain. Changing the amount of nonforage NDF does not often affect DMI (Allen, 2000). The decrease in DMI during and after the acidosis bout was similar to what has been reported in goats (Desnoyers et al., 2009). Although cows fed the high-starch diet had greater DMI than those fed the control diet, this did 


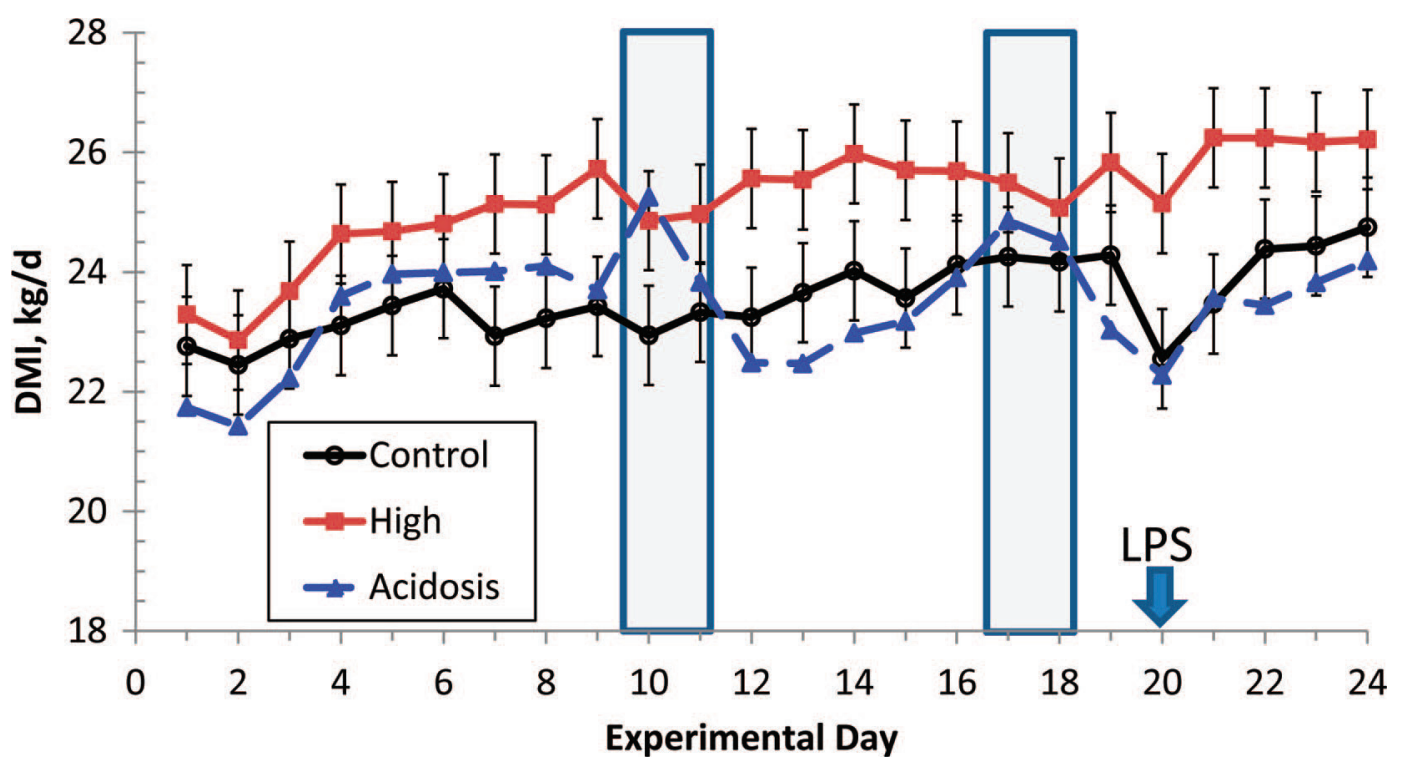

Figure 1. Effects of feeding different concentrations of starch continuously (control and high-starch treatments) or inconsistently on DMI. Acidosis treatment cows were fed the control diet during most of the experiment, except during two 2-d bouts (designated by shaded boxes) when they were fed an acidosis-inducing diet. All cows received an intramammary gland infusion of LPS in the morning of d 20. Prior to LPS infusion, cows fed the high-starch diet had higher DMI than cows fed the control diet $(P<0.02)$, but DMI was similar for cows fed the control or acidosis treatment $(P>0.85)$. Prior to LPS infusion, a treatment by day interaction was observed $(P<0.01)$ in that DMI was not affected by day for cows on the control or high-starch diet $(P>0.10)$, but day did affect DMI $(P<0.01)$ for cows on the acidosis treatment. Color version available online.

not translate into greater milk yields (Table 3 ). Unlike DMI, no treatment by time interaction was observed for milk yield (Figure 2). Milk protein yield (data not shown) and concentrations (Table 3) were not affected by treatment and responses over time were similar among treatments. Concentrations of MUN (Table 3; Figure 3) were lower for cows fed high starch compared with low starch $(P<0.04)$, as expected (Weiss et al.,

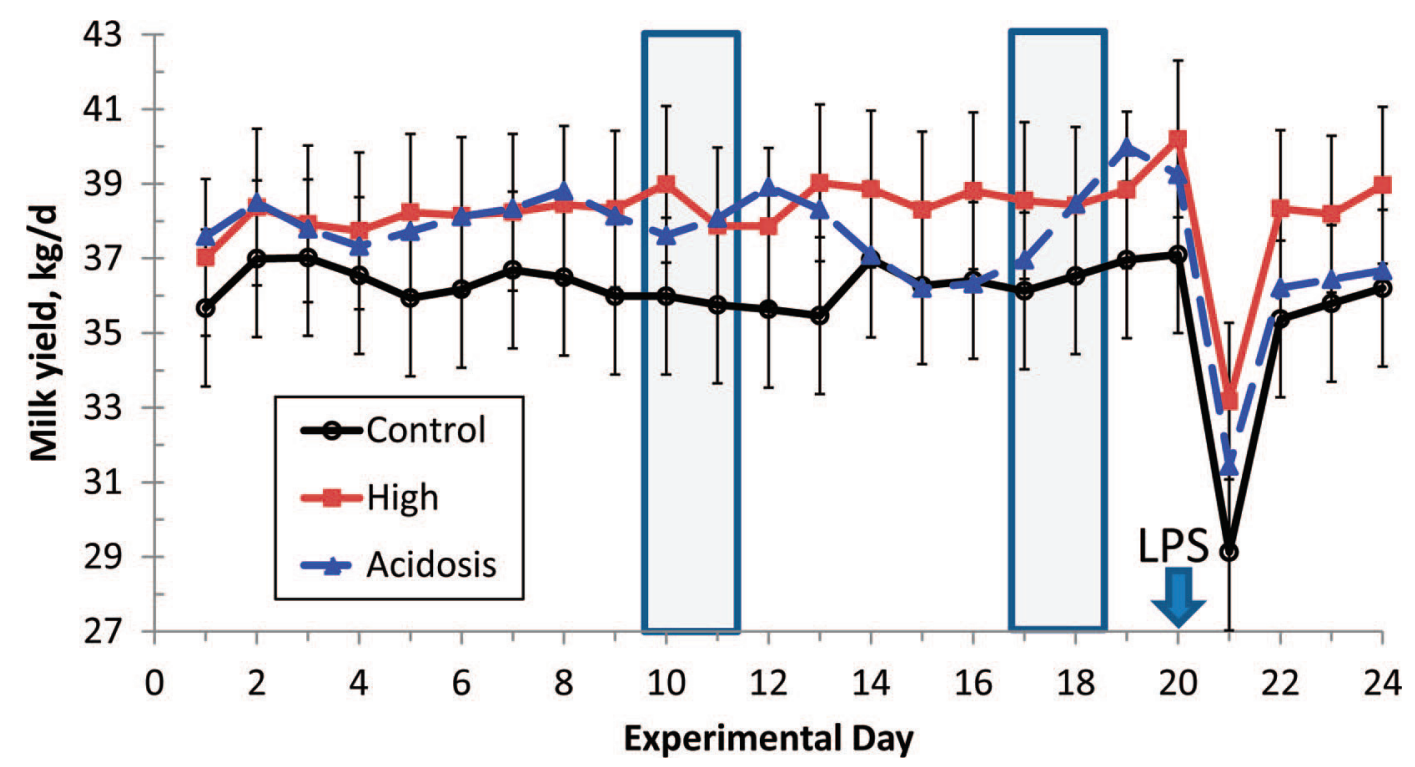

Figure 2. Effects of feeding different concentrations of starch continuously (control and high-starch treatments) or inconsistently on milk yield. Acidosis treatment cows were fed the control diet during most of the experiment, except during two 2-d bouts (designated by shaded boxes) when they were fed an acidosis-inducing diet. All cows received an intramammary gland infusion of LPS in the morning of d 20. No treatment effects or interactions were observed $(P>0.25)$. Color version available online. 


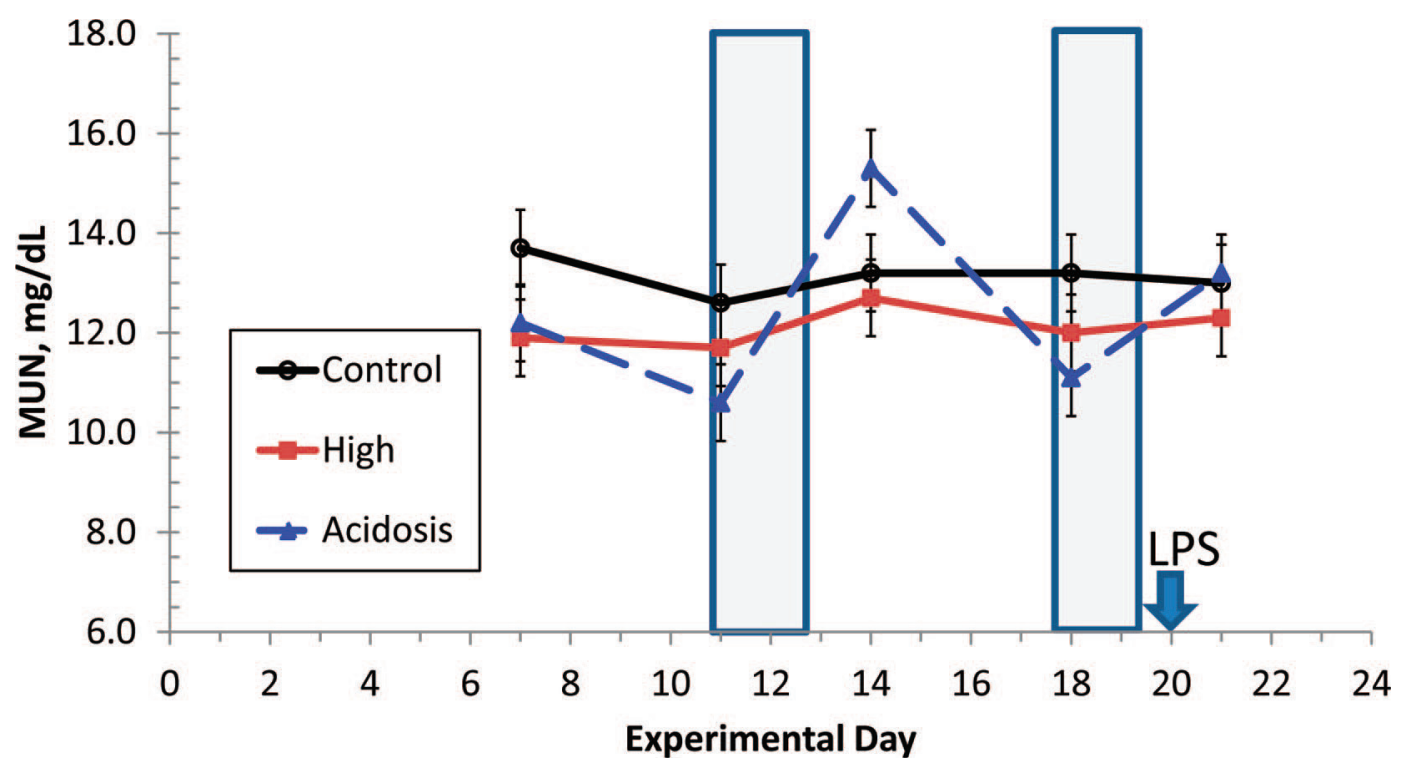

Figure 3. Effects of feeding different concentrations of starch continuously (control and high-starch treatments) or inconsistently on concentrations of MUN. Acidosis treatment cows were fed the control diet during most of the experiment, except during two 2-d bouts (designated by shaded boxes) when they were fed an acidosis-inducing diet. All cows received an intramammary gland infusion of LPS in the morning of d 20. Concentrations differed between cows fed control and high-starch diets $(P<0.04)$, but not between cows fed the control and acidosis treatments $(P>0.17)$. Various time by treatment interactions were also observed $(P<0.05)$. Color version available online.

2009). Overall, the acidosis treatment did not affect MUN compared with control, but the time profile (Figure 3) was different than for cows on control or high-starch diet (interaction; $P<0.05$ ). Concentrations of MUN were constant over time for both the control and high-starch treatments; however, for the acidosis treatment, MUN decreased during the acidosis bouts and spiked $1 \mathrm{~d}$ following the first bout.

\section{Milk Fat and Milk FA}

Milk fat depression and changes in concentrations of specific milk FA can be indicators of SARA (Kalscheur et al., 1997; Enjalbert et al., 2008; Colman et al., 2010, 2013). Similar to a previous experiment (Weiss, 2012), cows fed the high-starch diet had reduced milk fat concentrations compared with cows fed the control diet (Table 3).

Over the entire period, cows on the acidosis bout regimen did not have milk fat depression (Table 3). A possible explanation for the lack of a difference between control and acidosis bout regimen is that for 16 of the $20 \mathrm{~d}$ of the experiment cows on both treatments were fed the same diet; therefore, the effect of the acidosis bout diet (fed for $4 \mathrm{~d}$ ) would be diluted by the days when cows were fed the same diet. However, no day by treatment interaction was observed $(P>0.45)$ and no change in milk fat percent over days was observed for any treatment (data not shown). Another possibility is that 2 -d bouts were not long enough to elicit a change in milk fat percent, although it was long enough to elicit the expected change in milk FA (discussed herein). Milk fat percentage also was not depressed in other studies (Krause and Oetzel, 2005; Krause et al., 2009) with short-term (a few days) feeding of acidosisinducing diets.

Cows fed acidosis-inducing diets produce milk with altered concentrations of specific trans, odd-, and branched-chained FA (Enjalbert et al., 2008; Colman et al., 2010, 2013). Compared with cows fed the control diet, milk fat from cows fed the high-starch diet had greater concentrations of $\mathrm{C} 18: 1$ trans-10, C18:2 trans10, cis-12, and most odd-chained FA and lower concentrations of most branch-chained FA (Table 3). Generally, the same overall treatment effects were observed comparing the acidosis treatment with the control. Day by treatment interactions were observed for C18:1 trans-10 and for most odd- and branched-chain FA. For all FA with a day by treatment interaction, day had no effect for cows fed the control or high-starch diets $(P>$ $0.5)$, but for cows fed the acidosis regimen, results were affected $(P<0.01)$ by day. Cows on the control and high-starch diets were fed the same diet throughout the experiment. The temporal pattern observed for cows on the acidosis regimen was consistent for all FA that had a day by treatment interaction and reflects the days when the acidosis diet was fed (Figure 4). The treatment responses and the treatment by day interaction are consistent with other studies (Colman et al., 2010, 2013) that fed acidosis-inducing diets. In those studies, 

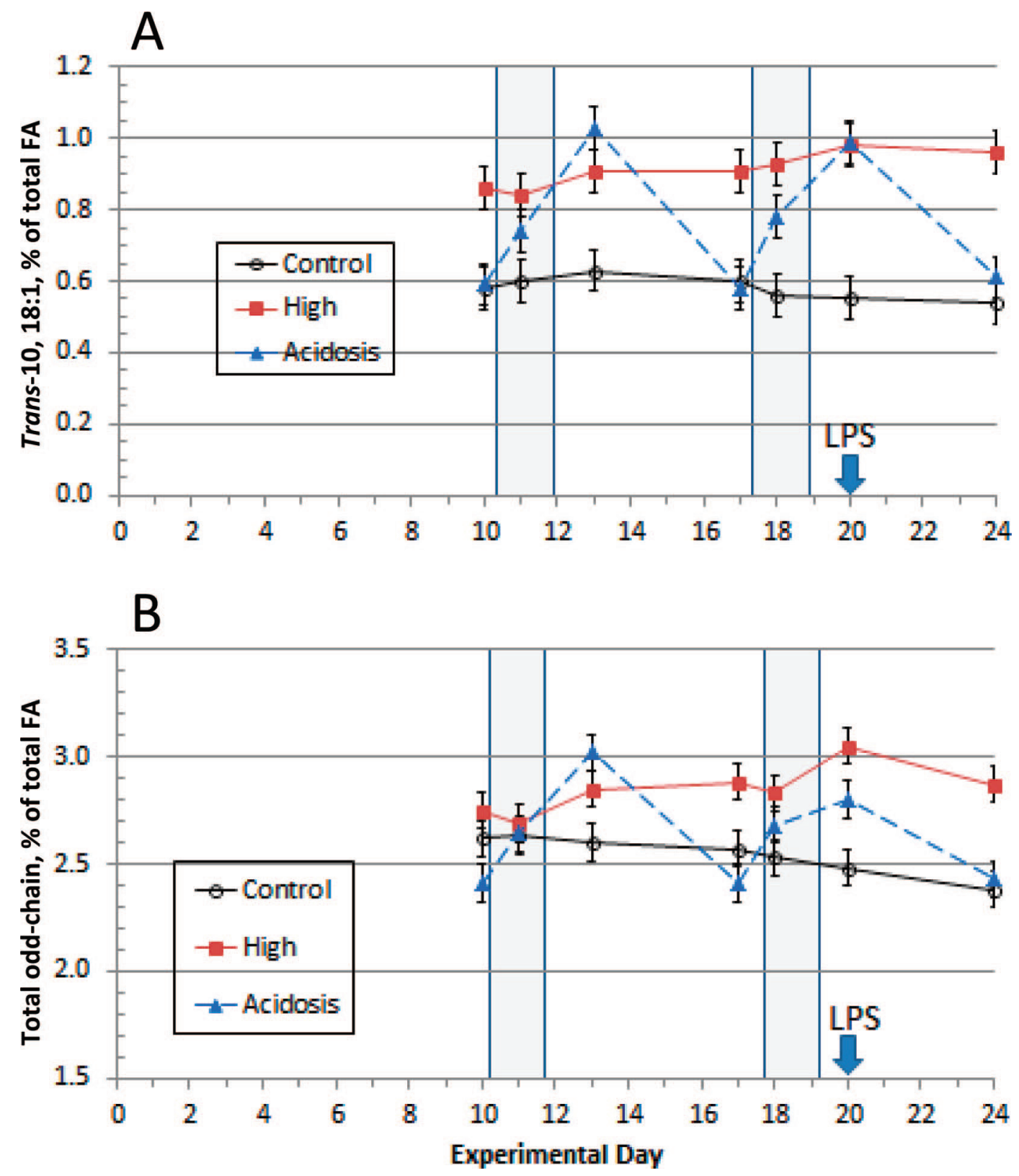

Figure 4. Effects of feeding different concentrations of starch continuously (control and high-starch treatments) or inconsistently on concentrations of C18:1 trans-10 (A) and total odd-chain FA (B) in milk fat. Acidosis treatment cows were fed the control diet during most of the experiment, except during two 2-d bouts (designated by shaded boxes) when they were fed an acidosis-inducing diet. All cows received an intramammary gland infusion of LPS in the morning of d 20. Concentrations differed between cows fed control and high-starch diets $(P<0.03)$ and between control and acidosis treatments $(P<0.01)$. Various time by treatment interactions were also observed $(P<0.05)$. Color version available online.

ruminal $\mathrm{pH}$ was monitored and indicated that acidosis was occurring. The changes in milk FA we observed with the high-starch and acidosis treatments indicate altered rumen conditions consistent with SARA.

\section{Clinical and Amyloid A Responses}

Evidence is mounting that SARA elicits systemic inflammation mediated by production of LPS in the ru- men (Gozho et al., 2005, 2006; Emmanuel et al., 2008; Khafipour et al., 2009). Concentrations of SAA in peripheral blood were greater $(P<0.05)$ for cows on the acidosis treatment than cows fed the control diet (blood samples were taken only during acidosis bouts; Table 4). No differences in SAA were found between cows fed the control or high-starch diet (Table 4). Emmanuel et al. (2008) reported elevated concentrations of ruminal LPS in cows fed diets with 30 or $45 \%$ barley grain com- 
Table 4. Effects of long- and short-term feeding of high-starch diets to dairy cows on concentration of serum amyloid A, rectal temperature, and rumen motility ${ }^{1}$

\begin{tabular}{lccccccc}
\hline & \multicolumn{3}{c}{ Treatment $^{2}$} & & \multicolumn{2}{c}{ Contrast $^{3}$} \\
\cline { 2 - 4 } Item & $\mathrm{C}$ & $\mathrm{H}$ & $\mathrm{A}$ & & SEM & C vs. H & C vs. A \\
\hline Serum amyloid A, ug/mL & 28.9 & 25.8 & 51.3 & & 7.13 & $<0.8$ & $<0.04$ \\
Temperature, ${ }^{\circ} \mathrm{C}$ & 38.3 & 38.2 & 38.2 & & 0.05 & $<0.22$ & $<0.19$ \\
Rumen contractions $/ \mathrm{min}$ & 1.96 & 1.91 & 1.74 & & 0.14 & $<0.5$ & $<0.01$ \\
\hline
\end{tabular}

${ }^{1}$ These samples and measurements were taken before LPS challenge on days when cows on the acidosis treatment were being fed the acidosis-inducing diet. No treatment by day interactions were observed for any variable $(P>0.15)$, but a day effect $(P<0.01)$ was noted for serum amyloid $\mathrm{A}$ in that samples collected on $\mathrm{d} 11$ (first bout), which had greater concentrations than those collected on $\mathrm{d} 18$.

${ }^{2}$ Cows on the control $(\mathrm{C})$ and high-starch $(\mathrm{H})$ treatments were fed the diets continuously during the experiment. Cows on the acidosis (A) treatment were fed the $\mathrm{C}$ diet during most of the experiment but were fed an acidosis-inducing diet during two 2-d feeding bouts.

${ }^{3}$ Main effect contrasts compared effects of longer term feeding of different starch concentrations (C vs. H) and effects of abrupt short-term feeding of higher starch (C vs. A).

pared with those fed 0 or $15 \%$ (barley grain replaced barley silage in the diets) for $21 \mathrm{~d}$. This likely caused the observed increase in serum LPS binding protein and SAA concentrations for the high-barley treatments. Likewise, Gozho et al. (2005) reported elevated SAA and ruminal LPS when SARA was abruptly induced by feeding a wheat and barley grain pellet. Although LPS was not measured in our experiment, ruminal LPS is often elevated when SAA is elevated. If this was occurring in our experiment, the elevated ruminal LPS could be inducing a systemic endotoxin response which could lead to ET and a blunted response to LPS challenge (discussed herein). Rectal temperature was not altered when cows were fed the acidosis-inducing diet; however, rumen motility was reduced $(P<0.05)$ compared with cows fed the control diet (Table 4).

\section{Response to LPS Intramammary Challenge}

Milk production and DMI decreased the day of the LPS challenge for all treatments (Figures 1 and 2). Milk yields on all treatments were lower $(P<0.05)$ on all days following LPS infusion than on d 20 (the day immediately before challenge), and milk yield the day of LPS challenge was lower $(P<0.01)$ than on all other days. Milk yield the day cows were infused with LPS averaged $84 \%$ of their preceding 7 -d average milk yield, and that percentage decline did not differ between treatments $(P>0.25)$. Dry matter intake on the day of LPS challenge was lower $(P<0.05)$ than all other days, but no other differences among days was observed. The day effect on DMI did not differ among treatments (treatment by day interaction; $P<0.45$ ). Compared with

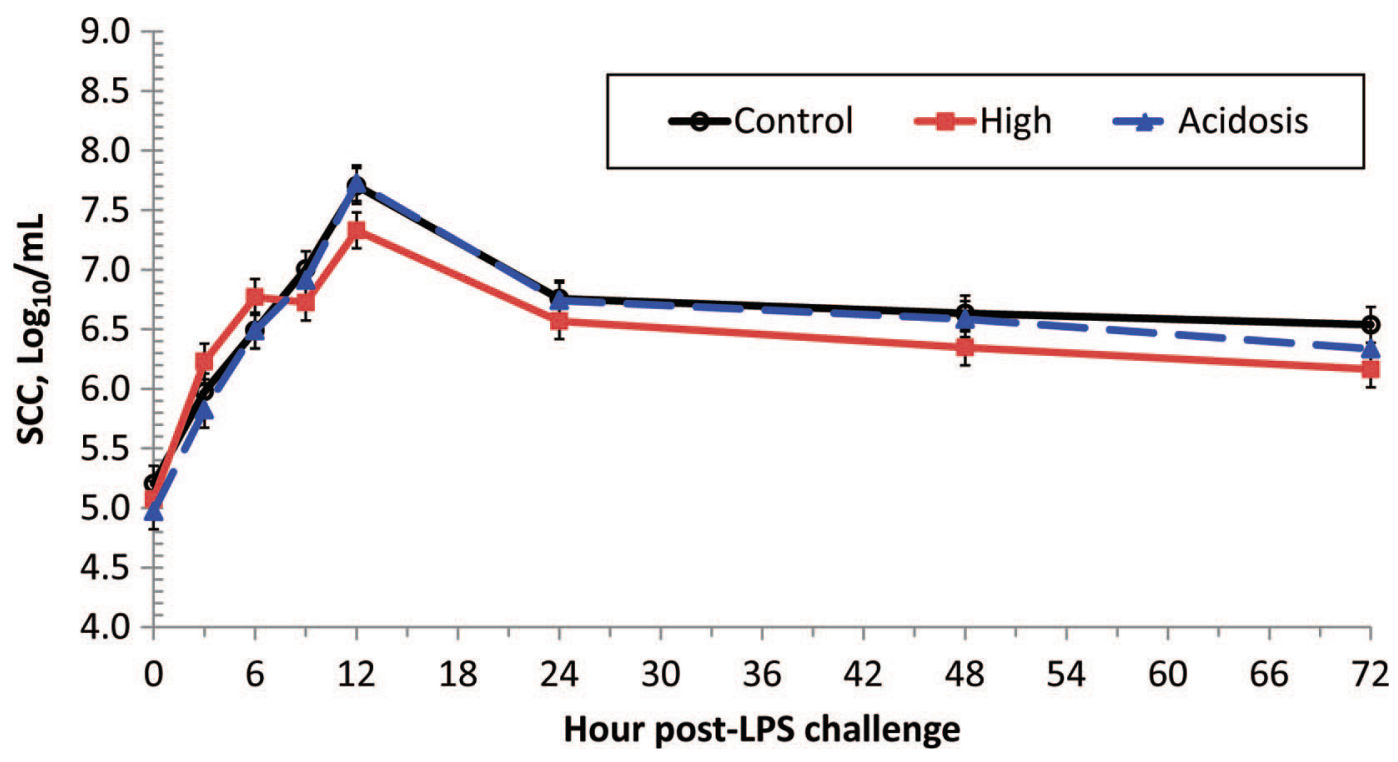

Figure 5. Effects of feeding different concentrations of starch continuously (control and high-starch treatments) or feeding an acidosisinducing diet for two 2-d bouts before infusing the mammary gland with LPS on milk SCC. Color version available online. 


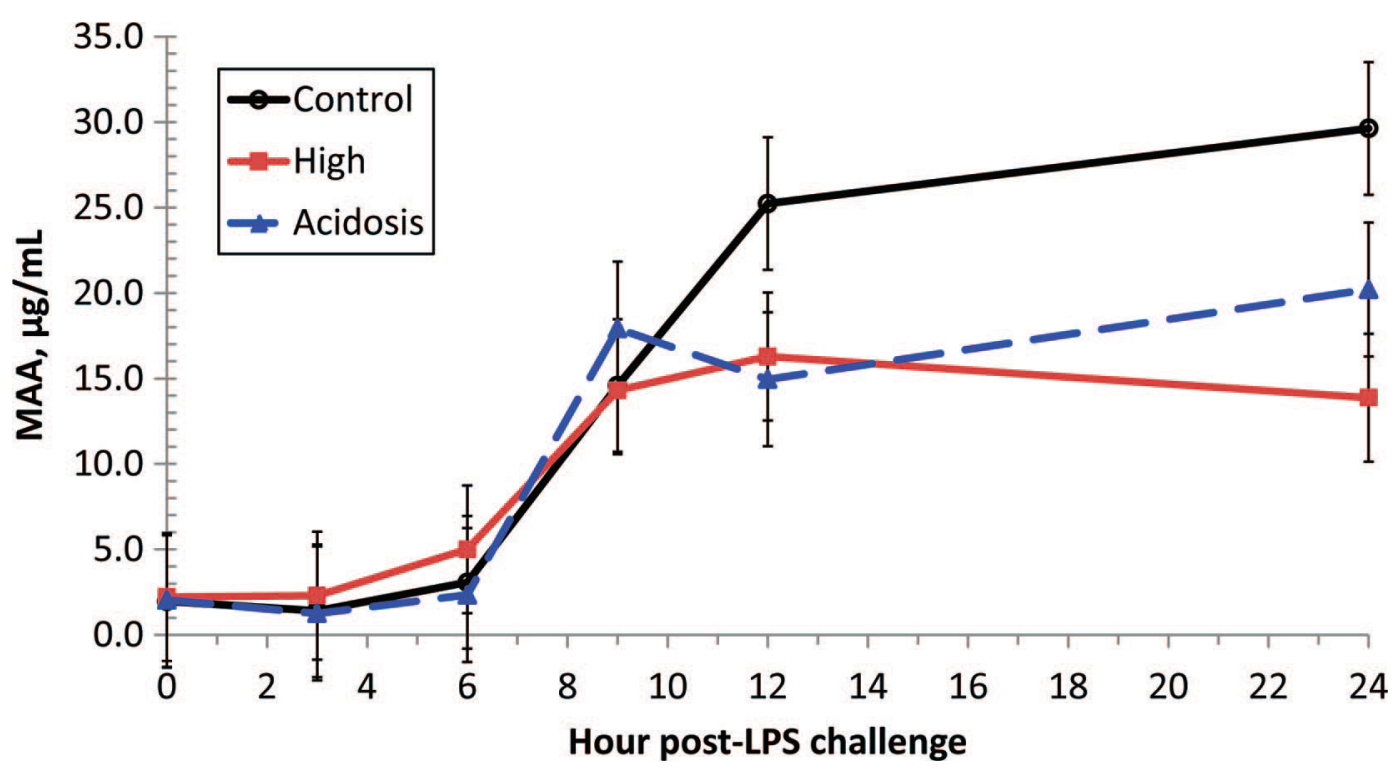

Figure 6. Effects of feeding different concentrations of starch continuously (control and high-starch treatments) or feeding an acidosisinducing diet for two 2-d bouts before infusing the mammary gland with LPS on concentrations of milk amyloid A (MAA). Color version available online.

the preceding 7-d average DMI, intake was reduced by $5 \%$ on the day of the LPS infusion. Rectal temperature following LPS infusion peaked $6 \mathrm{~h}$ postinfusion at $40^{\circ} \mathrm{C}$ (not affected by treatment) and then declined to normal $\left(38.4^{\circ} \mathrm{C}\right.$ ) by $12 \mathrm{~h}$ postinfusion (not affected by treatment, data not shown). Clinical mastitis score peaked at 6 to $9 \mathrm{~h}$ postinfusion (average $=3.5$ ), and then slowly declined to 2.8 at $72 \mathrm{~h}$. Averaged over time, cows on the high-starch diet had a lower score $(P<0.05)$ than cows on the control diet (2.9 vs. 2.6). Averaged over time, SCC for control and acidosis treatments were similar $(P>0.19)$, but SCC was lower $(P<0.05)$ for cows fed the high-starch diet than cows fed the control diet [6.40 vs. $6.56 \log (10) / \mathrm{mL} ; \mathrm{SE}=0.058]$. The change in SCC followed similar patterns (Figure 5) for all treatments (i.e., no treatment by time interaction; $P>0.25$ ). The SCC of unchallenged quarters did not differ among control, acidosis, and high-starch cows [5.05, 4.90, and $5.04 \log (10) / \mathrm{mL}$, respectively; $\mathrm{SE}=0.11]$ immediately before challenge. Daily mean SCC of unchallenged quarters remained unchanged during the challenge period for control, acidosis, and high-starch cows [4.47, 4.51, and $4.39 \log (10) / \mathrm{mL}$, respectively; $\mathrm{SE}=0.16]$.

The concentration of MAA was affected by time and treatment (Figure 6). Cows fed the high-starch diet or the acidosis bout regimen had peak MAA concentrations $9 \mathrm{~h}$ post-LPS infusion, whereas cows fed the control diet peaked at $12 \mathrm{~h}$. For cows fed the high-starch diet, concentrations of MAA were lower than cows fed the control diet at $12(P<0.06)$ and $24 \mathrm{~h}(P<0.06)$. Concentrations of MAA for cows on the acidosis bout treatment were lower than cows on the control diet at
$12 \mathrm{~h}(P<0.05)$, but concentrations did not differ at $24 \mathrm{~h}(P>0.20)$. A repeatable increase in concentration of MAA during intramammary inflammation has been previously established (Neilsen et al., 2004). Results of the current trial indicate intake of dietary starch altered the MAA response following LPS intramammary challenge. Whereas deciphering the mechanism for this alteration of MAA was not within the scope of the current trial, this observation was consistent with the hypothesis that SARA has potential suppressive effects on the host response to LPS challenge.

The manifestation of ET differs greatly among species, duration of exposure to subclinical concentrations of LPS, and route and concentration of both priming and challenge doses of LPS (Cross, 2002; Morris and $\mathrm{Li}, 2012)$. The hypothesis of the current trial was the induction of SARA in cows fed high-starch diets (for short or long periods) would cause liberation of LPS from gram-negative rumen flora, thus creating endogenous priming for ET to occur. Attempting to elicit an endogenous release of LPS differs from most previous experimental procedures when priming was accomplished by multiple injections of subacute concentrations of LPS (reviewed by Cross, 2002). However, the suppression of local mammary inflammatory responses observed was within the magnitude of repressed reactions in other species using exogenous LPS to prime for ET induction. The results of the current study indicated a mild, local hyporesponsiveness to intramammary LPS challenge in cows fed the high-starch diet compared with cows fed the control diet. The reduction was in peak inflammatory responses of MAA, SCC, and 
udder clinical scores following LPS challenge. Systemic clinical signs of LPS challenge, such as changes in rectal temperature, milk production, and DMI, did not differ between treatments. These results may offer an insight into possible correlations observed between metabolic disorders, inflammation, and the occurrence of mastitis in dairy cows (Sordillo et al., 2009).

\section{REFERENCES}

Allen, M. S. 2000. Effects of diet on short-term regulation of feed intake by lactating dairy cows. J. Dairy Sci. 83:1598-1624.

AOAC International. 2000. Official Methods of Analysis. Vol. 1 and 2. 17th ed. AOAC International, Gaithersburg, MD.

Beeson, P. B. 1947. Tolerance to bacterial pyrogens. I. Factors influencing its development. J. Exp. Med. 86:29-38.

Beutler, B., and E. T. Rietschel. 2003. Innate immune sensing and its roots: The story of endotoxin. Nat. Rev. Immunol. 3:169-176.

Bieniek, K., A. Szuster-Ciesielska, T. Kamińska, M. Kondracki, M. Witek, and M. Kandefer-Szerszeń. 1998. Tumor necrosis factor and interferon activity in the circulation of calves after repeated injection of low doses of lipopolysaccharide. Vet. Immunol. Immunopathol. 62:297-307.

Colman, E., W. B. Fokkink, M. Craninx, J. R. Newbold, B. D. Baets, and V. Fievez. 2010. Effect of induction of subacute ruminal acidosis on milk fat profile and rumen parameters. J. Dairy Sci. 93:4759-4773.

Colman, E., E. Khafipour, B. Vlaeminck, B. De Baets, J. C. Plaizier, and V. Fievez. 2013. Grain-based versus alfalfa-based subacute ruminal acidosis induction experiments: Similarities and differences between changes in milk fatty acids. J. Dairy Sci. 96:4100-4111.

Cross, A. S. 2002. Endotoxin tolerance - Current concepts in historical perspective. J. Endotoxin Res. 8:83-98.

Desnoyers, M., D. Sauvant, C. Duvaux-Ponter, and S. Giger-Reverdin 2009. Modeling of off-feed periods caused by subacute acidosis in intensive lactating ruminants: Application to goats. J. Dairy Sci. 92:3894-3906.

Elsasser, T. H., M. Richards, R. Collier, and G. F. Hartnell. 1996. Physiological responses to repeated endotoxin challenge are selectively affected by recombinant bovine somatotropin administration to calves. Domest. Anim. Endocrinol. 13:91-103.

Emmanuel, D. G. V., S. M. Dunn, and B. N. Ametaj. 2008. Feeding high proportions of barley grain stimulates an inflammatory response in dairy cows. J. Dairy Sci. 91:606-614.

Enjalbert, F., M. C. Videau, M. C. Nicot, and A. Troegeler-Meynadier. 2008. Effects of induced subacute ruminal acidosis on milk fat content and milk fatty acid profile. J. Anim. Physiol. Anim. Nutr. (Berl.) 92:284-291.

Garrett, E. F., M. N. Pereira, K. V. Nordlund, L. E. Armentano, W. J. Goodger, and G. R. Oetzel. 1999. Diagnostic methods for the detection of subacute ruminal acidosis in dairy cows. J. Dairy Sci. 82:1170-1178.

Goering, H. K., and P. J. V. Soest. 1970. Forage Fiber Analysis. Agric. Handbook 379. USDA, Washington, DC.

Gozho, G. N., D. O. Krause, and J. C. Plaizier. 2006. Rumen lipopolysaccharide and inflammation during grain adaptation and subacute ruminal acidosis in steers. J. Dairy Sci. 89:4404-4413.

Gozho, G. N., J. C. Plaizier, D. O. Krause, A. D. Kennedy, and K. M. Wittenberg. 2005. Subacute ruminal acidosis induces ruminal lipopolysaccharide endotoxin release and triggers an inflammatory response. J. Dairy Sci. 88:1399-1403.

Hogan, J., and K. L. Smith. 2003. Coliform mastitis: Review article. Vet. Res. 34:507-519.

Hogan, J. S., W. P. Weiss, D. A. Todhunter, K. L. Smith, and P. S. Schoenberger. 1992. Efficacy of an Escherichia coli J5 mastitis vaccine in an experimental challenge. J. Dairy Sci. 75:415-422.

Kalscheur, K. F., B. B. Teter, L. S. Piperova, and R. A. Erdman. 1997. Effect of dietary forage concentration and buffer addition on duodenal flow of trans-C18:1 fatty acids and milk fat production in dairy cows. J. Dairy Sci. 80:2104-2114.

Keunen, J. E., J. C. Plaizier, L. Kyriazakis, T. F. Duffield, T. M. Widowski, M. I. Lindinger, and B. W. McBride. 2002. Effects of a subacute ruminal acidosis model on the diet selection of dairy cows. J. Dairy Sci. 85:3304-3313.

Khafipour, E., D. O. Krause, and J. C. Plaizier. 2009. A grain-based subacute ruminal acidosis challenge causes translocation of lipopolysaccharide and triggers inflammation. J. Dairy Sci. 92:10601070

Kleen, J. L., G. A. Hooijer, J. Rehage, and J. P. T. M. Noordhuizen. 2003. Subacute ruminal acidosis (SARA): A review. J. Vet. Med. A Physiol. Pathol. Clin. Med. 50:406-414.

Kramer, J. K. G., V. Fellner, M. E. R. Dugan, F. D. Sauer, M. M. Mosoba, and M. P. Yurawecz. 1997. Evaluating acid and base catalysts in the methylation of milk and rumen fatty acids with special emphasis on conjugated dienes and total trans fatty acids. Lipids $32: 1219-1228$

Krause, K. M., D. V. Dhuyvetter, and G. R. Oetzel. 2009. Effect of a low-moisture buffer block on ruminal $\mathrm{pH}$ in lactating dairy cattle induced with subacute ruminal acidosis. J. Dairy Sci. 92:352-364.

Krause, K. M., and G. R. Oetzel. 2005. Inducing subacute ruminal acidosis in lactating dairy cows. J. Dairy Sci. 88:3633-3639.

McBeth, L. R., N. R. St-Pierre, D. E. Shoemaker, and W. P. Weiss. 2013. Effects of transient changes in silage dry matter concentration on lactating dairy cows. J. Dairy Sci. 96:3924-3935.

Morris, M., and L. Li. 2012. Molecular mechanisms and pathological consequences of endotoxin tolerance and priming. Arch. Immunol. Ther. Exp. (Warsz.) 60:13-18.

Nagaraja, T. G., E. E. Bartley, L. R. Fina, H. D. Anthony, and R. M. Bechtle. 1978. Evidence of endotoxins in the rumen bacteria of cattle fed hay or grain. J. Anim. Sci. 47:226-234.

National Mastitis Council. 2004. Microbial Procedures for the Diagnosis of Bovine Udder Infection and Determination of Milk Quality. National Mastitis Council, Verona, WI.

Neilsen, B. H., S. Jacobsen, P. H. Andersen, T. A. Niewold, and P. M. H. Heegaard. 2004. Acute phase protein concentrations in serum and milk from healthy cows, cows with clinical mastitis, and cows with extra-mammary inflammatory conditions. Vet. Rec. 154:361-365.

NRC. 2001. Nutrient Requirements of Dairy Cattle, 7th rev. ed. Natl. Acad. Press, Washington D.C.

Perkins, K. H., M. J. Vandehaar, J. L. Burton, J. S. Liesman, R. J. Eskine, and T. H. Elsasser. 2002. Clinical responses to intramammary endotoxin infusion in dairy cows subjected to feed restriction. J. Dairy Sci. 85:1724-1731.

Sanchez-Cantu, L., H. N. Rode, and N. V. Christou. 1989. Endotoxin tolerance is associated with reduced secretion of tumor necrosis factor. Arch. Surg. 124:1432-1435.

SAS Institute. 2009. SAS/STAT 9.2 User's Guide, 2nd ed. SAS Inst. Inc. Cary, NC.

Sordillo, L. M., G. A. Contreras, and S. L. Aitken. 2009. Metabolic factors affecting the inflammatory response of periparturient dairy cows. Anim. Health Res. Rev. 10:53-63.

Van Soest, P. J., J. B. Robertson, and B. A. Lewis. 1991. Methods for dietary fiber, neutral detergent fiber, and nonstarch polysaccharides in relation to animal nutrition. J. Dairy Sci. 74:3583-3597.

Weiss, W. P. 2012. Use of a corn milling product in diets for dairy cows to alleviate milk fat depression. J. Dairy Sci. 95:2081-2090.

Weiss, W. P., N. R. St-Pierre, and L. B. Willett. 2009. Varying type of forage, concentration of metabolizable protein, and source of carbohydrate affects nutrient digestibility and production by dairy cows. J. Dairy Sci. 92:5595-5606.

Weiss, W. P., and D. J. Wyatt. 2000. Effect of oil content and kernel processing of corn silage on digestibility and milk production by dairy cows. J. Dairy Sci. 83:351-358.

Weiss, W. P., and D. J. Wyatt. 2003. Effect of dietary fat and vitamin $\mathrm{E}$ on $\alpha$-tocopherol in milk from dairy cows. J. Dairy Sci. $86: 3582-3591$. 